\title{
Sigmoidoscopy and cytology in the detection of microscopic disease of the rectal mucosa in ulcerative colitis
}

\author{
J. McK. WATTS, H. THOMPSON, AND J. C. GOLIGHER \\ From the Colitis Clinic, The General Infirmary at Leeds
}

EDITORIAL SYNOPSIS This study confirms the value of both the sigmoidoscopic assessment and the cytology of the mucosal secretion in the detection of microscopic disease of the rectal mucosa in ulcerative colitis. On certain occasions, however, microscopic disease is undetected using these methods, so that rectal biopsy is recommended as an aid in the diagnosis of patients with a history suggestive of colitis, but having normal or equivocal sigmoidoscopic appearances.

Inspection of the rectal mucous membrane at sigmoidoscopy is generally held to be the most valuable single diagnostic aid in ulcerative colitis. However, a recent study by Baron, Connell, and Lennard-Jones (1964) has demonstrated the difficulties encountered in the precise definition of the mucosal appearances in this disease, considerable discrepancies having been found in the verdicts of several independent observers on the sigmoidoscopic features of identical areas of mucosa.

The relationship between the sigmoidoscopic and microscopic appearances of the rectal mucous membrane in colitis has been studied by Truelove and Richards (1956), Dick and Grayson (1961), Matts (1961), and Flick, Voegtlin, and Rubin (1962). Each of these groups of workers has shown that microscopic inflammatory changes in rectal mucosa may be present when sigmoidoscopic appearances are normal, although in general a close correlation was observed between macroscopic and microscopic appearances.

In this paper we have attempted to evaluate the sigmoidoscopic appearances and the cytology of the mucosal secretion in ulcerative colitis by comparison with the histological findings in rectal biopsy specimens. As a preliminary step, data are provided on the observer variation in describing the macroscopic mucosal appearances in this disease, the most consistent terms being defined for use in recording sigmoidoscopic appearances.

CLINICAL MATERIAL AND METHODS OF INVESTIGATION

The study comprised 104 patients suffering from idiopathic ulcerative colitis currently attending the Colitis
Clinic, the severity of disease ranging from complete quiescence to severe activity, and the extent of disease varying from localized rectal involvement to complete rectal and colonic involvement at the time of examination; and, as normal controls, 22 patients with simple internal haemorrhoids and no history of colitis, who were undergoing routine sigmoidoscopy in the Rectal Clinic. The investigations relevant to the present study were:-

SIGMOIDOSCOPY This examination was performed on all patients. The macroscopic appearances were studied at one point, the instrument being held immovably in position while an assessment was made at that site. The findings were then recorded, the following descriptive characteristics being used.

$\begin{array}{ll}1 \text { General impression } & \left\{\begin{array}{l}\text { Normal } \\ \text { Abnormal }\end{array}\right. \\ \text { 2 Bleeding } & \left\{\begin{array}{l}\text { Present } \\ \text { Absent }\end{array}\right. \\ \text { 3 Vascular pattern } & \left\{\begin{array}{l}\text { Present } \\ \text { Present but abnormal } \\ \text { Absent }\end{array}\right. \\ 4 \text { Oedema } & \left\{\begin{array}{l}\text { Present } \\ \text { Absent }\end{array}\right. \\ \text { 5 Colour } & \left\{\begin{array}{l}\text { Abnormal pallor } \\ \text { Normal } \\ \text { Reddened }\end{array}\right. \\ \text { 6 Granularity } & \left\{\begin{array}{l}\text { Present } \\ \text { Absent }\end{array}\right. \\ 7 \text { Ulceration } & \left\{\begin{array}{l}\text { Present } \\ \text { Absent }\end{array}\right.\end{array}$

In order to test the consistency of these characteristics at sigmoidoscopy, on $\mathbf{3 0}$ occasions the area being studied was viewed in succession by two observers experienced in sigmoidoscopy, who then recorded their findings independently. 
CYTOLOGY OF THE MUCOSAL SECRETION A specimen of the surface secretion of the area of mucosa being studied was obtained on 52 occasions using the method of Anthonisen and Riis (1961). A circular coverslip, $10 \mathrm{~mm}$. in diameter, coated with albumin and held securely on a special carrier, was passed down the lumen of the sigmoidoscope and held in light contact with the mucosa for a few seconds. The cover slip was then dried in air, fixed in ether alcohol, and finally stained with haematoxylin and eosin. The cytology of the mucosal secretion was then examined and reported independently by a gastrointestinal pathologist, who was aware of neither the microscopic appearances of the biopsy nor of the clinical activity. The cytological appearance was graded into 'active' or 'inactive', according to the presence or absence of inflammatory cells in the mucosal exudate. The nature of any inflammatory cells was also noted.

BIOPSY OF THE MUCOUS MEMBRANE As a final step, after macroscopic examination of the selected area of mucous membrane, a biopsy was taken from this site. This was secured under direct vision by means of Lloyd Davies sigmoidoscopic biopsy forceps. No serious complications were encountered, although on a few occasions the patient reported the passage of small amounts of blood following the examination.

In all, 176 biopsies were performed, on several occasions biopsies being obtained in the same patient from two different areas of rectal mucosa. The specimens were immediately fixed in formol saline and serial sections were cut and stained with haematoxylin and eosin. The slides were then examined and reported on independently by a gastrointestinal pathologist, who was aware neither of the sigmoidoscopic appearances nor of the clinical diagnosis. The examination of serial sections was necessary in order to detect minor inflammatory changes in the lamina propria. The following microscopic grades of activity were recognized (Figure 1):-

Normal Epithelium normal (Fig.1a): small numbers of lymphocytes, plasma cells, macrophages, and mast cells are normally present in the lamina propria. Minimal intersitial oedema, occurring without epithelial or cellular changes, is accepted as being within the normal range of appearances.

Grade 1 No significant epithelial changes but increased numbers of chronic inflammatory cells in the lamina propria (Figure 1b). Occasional foci of polymorphonuclear leucocytes.

Grade 2 Mild epithelial changes, usually regenerative (Figure 1c). Leucocytes may be present within the crypts and ducts, and Paneth cells in the crypts. Severe inflammatory cellular infiltration, with lymphocytes, plasma cells, polymorphs, eosinophils and mast cells, is present in the lamina propria. Fibrosis may be present.

Grade 3 Severe inflammatory changes with evidence of crypt abscesses, inflammatory erosions and frank ulceration (Figure 1d). Occasional multinucleated giant cells are seen in the lamina propria.

No particular significance is attached to the occurrence of giant cell follicles in the rectal biopsies from four patients because their interpretation is controversial and their presence is of no apparent significance in this study.
It was considered that grade 1 represented the earliest or minimal microscopic change seen in ulcerative colitis. In order to test the ability of the pathologist to detect such minimal microscopic changes, 22 control biopsies were obtained from 22 normal patients undergoing routine sigmoidoscopy in the Rectal Clinic, none of whom had suffered from colitis. These biopsies were submitted for examination by the pathologist, amongst and indistinguishable from those obtained from colitic patients. The classification of these 22 biopsies can be seen in Table I. This illustrates that the normal range of histological appearance in rectal mucosa extends into our grade 1 category. The earliest signs of microscopic abnormality in colitic mucosa are therefore in all probability indistinguishable from the range of normal mucosal appearances.

\section{TABLE I}

HISTOLOGICAL GRADE IN 22 RECTAL BIOPSIES FROM 22 CONTROL PATIENTS NOT SUFFERING FROM ULCERATIVE COLITIS

Biopsy Grade Number of Biopsies

\begin{tabular}{cc} 
Biopsy Grade & Number of Biopsies \\
\hline Normal & 14 \\
Grade 1 & 8 \\
Grade 2 & 0 \\
Grade 3 & 0
\end{tabular}

RESULTS

OBSERVER VARIATION IN DESCRIPTION OF MUCOSAL APPEARANCES AT SIGMOIDOSCOPY A comparison of the sigmoidoscopic findings recorded by two independent observers in 30 patients, in which the same area of mucosa was examined, is presented in Table II. Each criterion of mucosal appearance will now be analysed separately.

Overall impression of mucosa Agreement was reached in 29 of 30 observations (97\%).

Bleeding It was not possible to state whether any bleeding observed was produced by contact or occurred spontaneously because the mucosa was viewed with the sigmoidoscope fixed in position. Bleeding was recorded as being either absent or present, agreement being reached in 28 of the 30 observations (93\%).

Vascular pattern Observations were made as to whether the mucosal vascular pattern was present, present but abnormal, or absent. The mucosal vascular pattern was recorded as 'present but abnornormal' on only three occasions, and on each occasion the other observer described the vascular pattern as being 'present'. This category was therefore regarded as unreliable, and in order to define the observer variation, these three observations 'present but abnormal' were regarded as vascular pattern 'present'. Agreement was then reached in 29 of 30 observations $(97 \%)$ on the presence or absence of mucosal vascular pattern. 


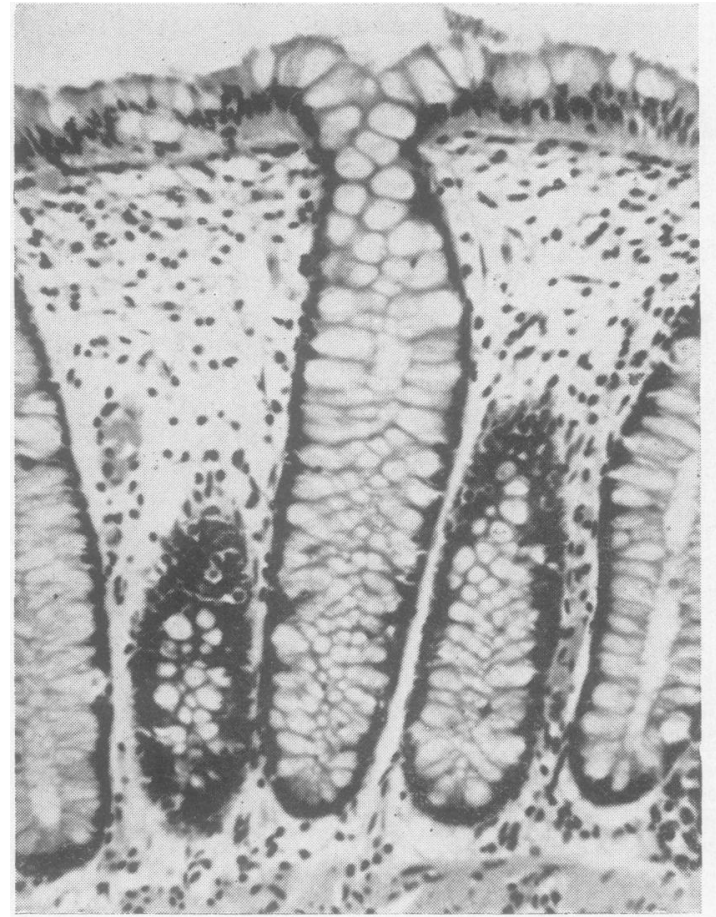

FIG. 1a.

FIGS. 1a and 1b. Normal colonic mucosa (Fig. la) and (Fig. 1b) cellular infiltration.

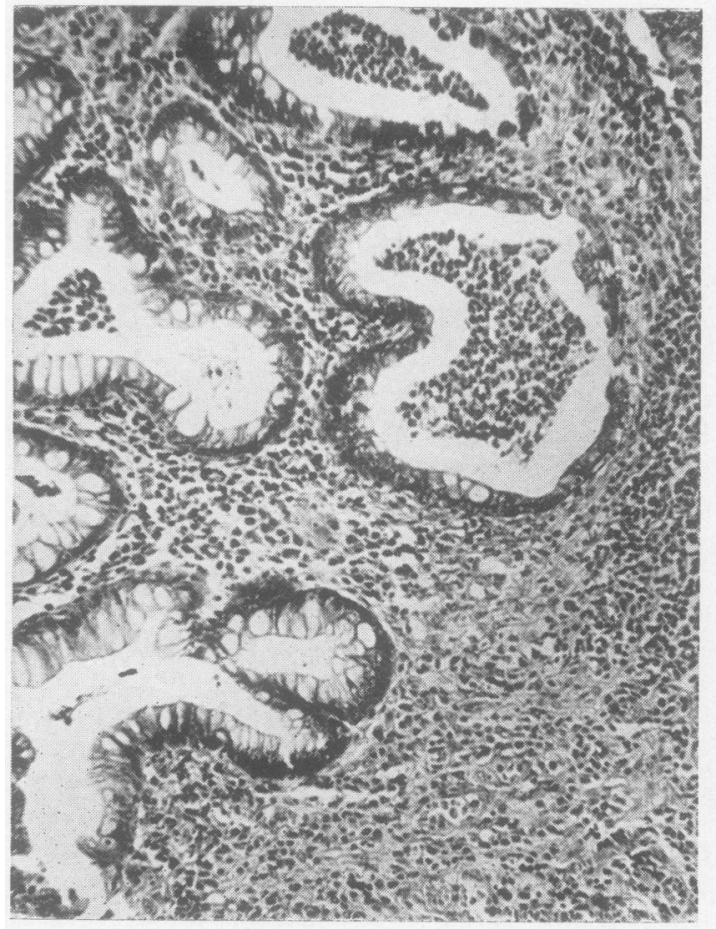

FIG. 1c.

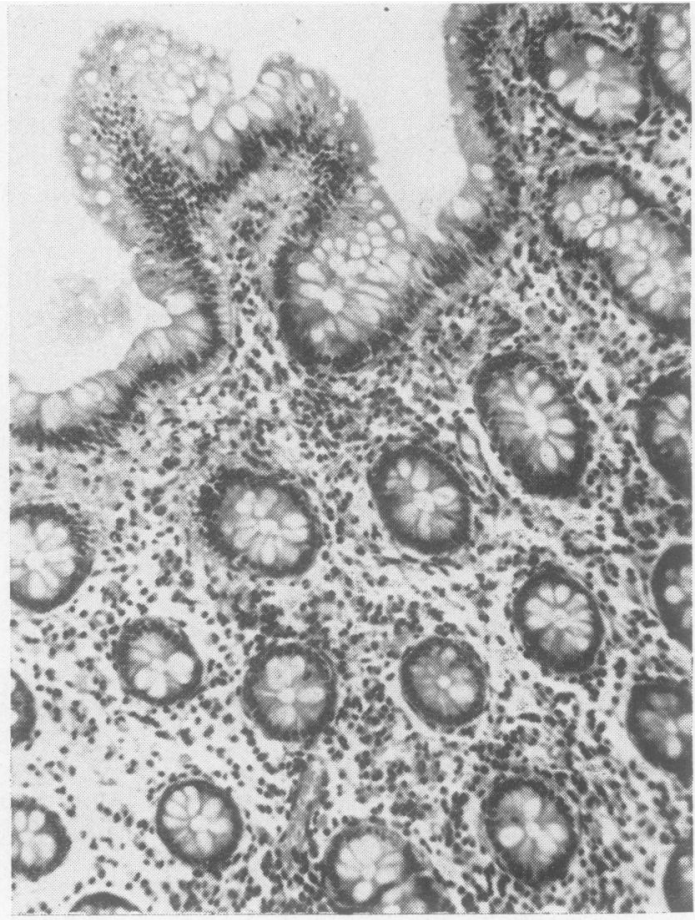

FIG. $1 \mathrm{~b}$.

FIGs. 1c and 1d. Grade 2: severe chronic inflammatory cellular infiltration with leucocytes in the ducts (Fig. Ic) and (Fig. 1d) grade 3: typical crypt abscess with regenerative changes in epithelium. All sections stained with Harris's haematoxylin and eosin $\times 66$.

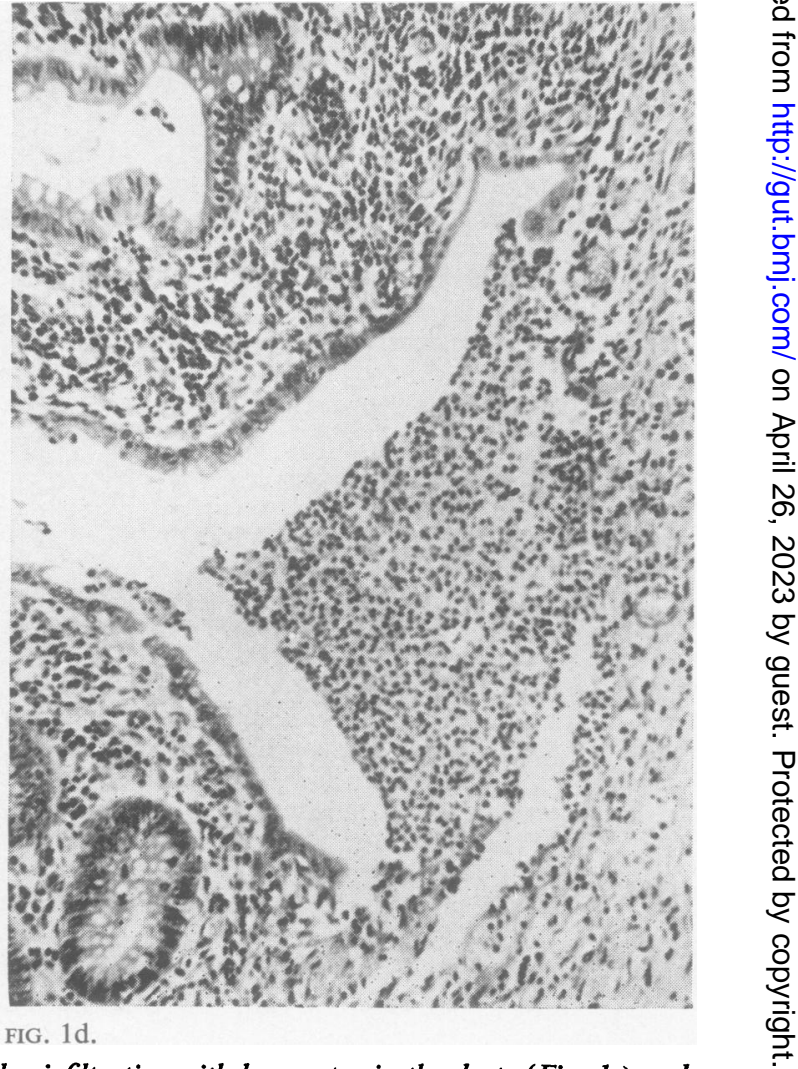


TABLE II

DESCRIPTIVE TERMS USED AT SIGMOIDOSCOPY AND RATES OF OBSERVER AGREEMENT

\begin{tabular}{|c|c|c|}
\hline $\begin{array}{l}\text { Descriptive } \\
\text { Term }\end{array}$ & Alternatives & $\begin{array}{l}\text { Incidence of Agree- } \\
\text { ment by Two } \\
\text { Observers }\end{array}$ \\
\hline General impression & $\begin{array}{l}1 \text { Normal } \\
2 \text { Abnormal }\end{array}$ & 29 of $30(97 \%)$ \\
\hline Bleeding & $\begin{array}{l}1 \text { Present } \\
2 \text { Absent }\end{array}$ & 28 of $30(93 \%)$ \\
\hline Vascular pattern & $\begin{array}{l}1 \text { Present (including } \\
\text { abnormal vascular } \\
\text { pattern) } \\
2 \text { Absent }\end{array}$ & 29 of $30(97 \%)$ \\
\hline Oedema & $\begin{array}{l}1 \text { Present } \\
2 \text { Absent }\end{array}$ & 25 of $30(83 \%)$ \\
\hline Colour & $\begin{array}{l}1 \text { Normal (including } \\
\text { abnormal pallor) } \\
2 \text { Reddened }\end{array}$ & 22 of $30(73 \%)$ \\
\hline Granularity & $\begin{array}{l}1 \text { Present } \\
2 \text { Absent }\end{array}$ & 19 of $30(63 \%)$ \\
\hline \multirow[t]{2}{*}{ Ulceration } & \multirow[t]{2}{*}{$\begin{array}{l}1 \text { Present } \\
2 \text { Absent }\end{array}$} & 30 of $30(100 \%)$ \\
\hline & & $\begin{array}{l}\text { (Ulceration present } \\
\text { in one patient } \\
\text { only) }\end{array}$ \\
\hline
\end{tabular}

Colour Observations were made on whether the mucosa was abnormally pale, of normal colour, or reddened. The observation 'abnormally pale' was recorded on only four occasions in three patients, agreement between the two observers being reached on only one occasion. This category is therefore regarded as unreliable. Using the three categories, agreement was reached in only 22 of $\mathbf{3 0}$ observations $(73 \%)$, although if 'abnormal pallor' was regarded as 'normal', agreement was reached in 24 of the 30 observations $(80 \%)$.

Granularity This feature was described as being present or absent. Agreement was reached in only 19 of the 30 observations $(63 \%)$, suggesting that this criterion is of little value in the description of mucosal appearances.

Oedema Describing oedema as being either present or absent, agreement was reached in 25 of 30 observations $(83 \%)$.

Ulceration Complete agreement was obtained over the presence or absence of ulceration. However, this finding gives no indication of observer variation as ulceration was only recorded in one of the $\mathbf{3 0}$ patients.

VALUE OF VARIOUS CRITERIA OF SIGMOIDOSCOPIC APPEARANCES The results of this study of observer variation in recording the mucosal appearances at sigmoidoscopy agree in principle with the results reported by Baron et al. (1964) from a similar, but more extensive investigation using three observers. It would appear that the only mucosal characteristics that can be used with any confidence are the following:- (1) Overall impression of normality or abnormality; (2) vascular pattern (presence or absence); (3) bleeding (presence or absence); (4) oedema (presence or absence).

In recording each of these characteristics an agreement rate of greater than $80 \%$ was achieved by the two observers. For the purpose of analysis of sigmoidoscopic appearances in relation to microscopic examination of mucosal biposies, we have therefore used only these characteristics.

SIGMOIDOSCOPIC APPEARANCES IN 22 CONTROL PATIENTS NOT SUFFERING FROM COLITIS The macroscopic characteristics described were recorded at the time of sigmoidoscopy and biopsy in all 22 control patients not suffering from colitis. All characteristics were recorded as being normal, except in three patients in whom the normal ramifying vascular pattern was absent at sites $8 \mathrm{~cm} ., 9 \mathrm{~cm}$., and $10 \mathrm{~cm}$., respectively, from the anal verge.

CORRELATION OF SIGMOIDOSCOPIC APPEARANCES WITH HISTOLOGICAL FINDINGS IN RECTAL BIOPSY SPECIMENS The results of this study are presented in Tables III to VIII.

TABLE III

VASCULAR PATTERN IN 22 NORMAL PATIENTS (22 BIOPSIES)

\begin{tabular}{ccc} 
Biopsy Grade & \multicolumn{2}{c}{ Vascular Pattern } \\
\cline { 2 - 3 } & Present & Absent \\
\hline Normal & 11 & $3^{1}$ \\
Grade 1 & 8 & 0 \\
Grade 2 & 0 & 0 \\
Grade 3 & 0 & 0
\end{tabular}

${ }^{1}$ Biopsies at $8 \mathrm{~cm} ., 9 \mathrm{~cm}$., and $10 \mathrm{~cm}$., respectively, from anal verge.

\section{TABLE IV}

VASCULAR PATTERN IN COLITIS PATIENTS (RECORDED IN 150 BIOPSIES)

\begin{tabular}{lcc} 
Biopsy Grade & \multicolumn{2}{c}{ Vascular Pattern } \\
\cline { 2 - 3 } & Present & Absent \\
\hline Normal & 28 & $4^{1}$ \\
Grade 1 & 29 & 22 \\
Grade 2 & 4 & 20 \\
Grade 3 & 1 & 42
\end{tabular}

${ }^{1}$ Biopsies at $4 \mathrm{~cm}$., $5 \mathrm{~cm}$., $7 \mathrm{~cm}$., and $8 \mathrm{~cm}$., respectively, from anal verge.

CORRELATION OF CYTOLOGY OF MUCOSAL SECRETION WITH HISTOLOGICAL APPEARANCES IN RECTAL BIOPSY SPECIMENS The mucosa was graded into 'active' or 'inactive' depending on the presence or absence, respectively, of inflammatory cells in the surface 
TABLE V

CONTACT BLEEDING IN COLITIS PATIENTS ${ }^{1}$ (RECORDED IN 155 BIOPSIES)

\begin{tabular}{lccc} 
Biopsy Grade & \multicolumn{2}{c}{ Contact } & Bleeding \\
\cline { 2 - 3 } & Absent & Present \\
\hline Normal & 32 & $2^{1}$ \\
Grade 1 & 38 & 13 \\
Grade 2 & 12 & 13 \\
Grade 3 & 4 & 41
\end{tabular}

${ }^{1}$ Vascular pattern present in both instances.

TABLE VI

OEDEMA IN COLITIS PATIENTS (RECORDED IN 135 BIOPSIES)

\begin{tabular}{lcc} 
Biopsy Grade & \multicolumn{2}{c}{ Oedema } \\
\cline { 2 - 3 } & Absent & Present \\
\hline Normal & 29 & 0 \\
Grade 1 & 42 & 6 \\
Grade 2 & 15 & 8 \\
Grade 3 & 11 & 24
\end{tabular}

TABLE VII

VASCULAR PATTERN ABSENT AND CONTACT BLEEDING PRESENT IN COLITIS PATIENTS ${ }^{1}$

Biopsy Grade Vascular Pattern Absent and Contact Bleeding Present

\begin{tabular}{ll}
\cline { 2 - 2 } Negative & Positive \\
\hline
\end{tabular}

Normal $34 \quad 0$

$\begin{array}{llr}\text { Grade } 1 & 38 & 13 \\ \text { Grade } 2 & 12 & 12\end{array}$

Grade $2 \quad 12 \quad 12$

$\begin{array}{lll}\text { Grade } 3 & 5 & 38\end{array}$

${ }^{1}$ Both parameters recorded in 152 biopsies.

TABLE VIII

OVERALL SIGMOIDOSCOPIC ASSESSMENT IN COLITIS PATIENTS (RECORDED IN ALL 157 BIOPSIES)

Biopsy Grade

Overall Assessment

\begin{tabular}{ccc} 
Biopsy Grade & \multicolumn{2}{c}{ Overall Assessment } \\
\cline { 2 - 3 } & Normal & Abnormal \\
\hline Normal & 29 & 6 \\
Grade 1 & 26 & 26 \\
Grade 2 & 5 & 20 \\
Grade 3 & 0 & 45
\end{tabular}

TABLE IX

ACTIVITY OF MUCOUS MEMBRANE IN 54 COLITIS PATIENTS ACCORDING TO CYTOLOGY OF SURFACE SECRETION COMPARED WITH HISTOLOGICAL GRADE OF MUCOSAL BIOPSY AT THAT SITE Biopsy Grade $\frac{\text { Grades of Activity }}{\text { Inactive }^{1} \text { Active }^{2}}$

$\begin{array}{crr}\text { Normal } & 8 & 2 \\ \text { Grade 1 } & 12 & 8 \\ \text { Grade 2 } & 2 & 8 \\ \text { Grade 3 } & 0 & 14 \\ { }^{1} \text { Inactive }=\text { no inflammatory cells present. } & \\ { }^{2} \text { Active }=\text { inflammatory cells present. } & \end{array}$

secretion. The results of this study in 54 patients are illustrated in Table IX.

The cytology of the active group usually consisted of large numbers of neutrophil and polymorphonuclear leucocytes. Eosinophilia was occasionally observed but this was not as common as described by Anthonisen and Riis (1962).

\section{DISCUSSION}

SIGMOIDOSCOPIC ASSESSMENT OF MICROSCOPIC DISEASE IN RECTAL MUCOSA At first sight it appears from these results that the various macroscopic abnormalities of the rectal mucosa seen on sigmoidoscopy are unreliable in the assessment of mucosal disease, if this is judged by the microscopic examination of biopsy specimens. This unreliability is reflected, both in the not uncommon failure of individual macroscopic parameters to detect even severe microscopic disease, and also in the large number of microscopically normal or near normal biopsies from mucosa reported to be macroscopically abnormal.

Each macroscopic characteristic will now be discussed separately in order to define its value and reliability.

Vascular pattern The absence of a normal ramifying vascular pattern is commonly regarded as one of the most valuable indices of mucosal abnormality in ulcerative colitis. It was surprising, therefore, to find that the vascular pattern was absent (at $8 \mathrm{~cm}$., $8 \mathrm{~cm}$., and $10 \mathrm{~cm}$. respectively from the anal verge) in three normal patients (Table II). In addition, four of 32 normal biopsies from colitic patients were taken from an area devoid of any normal vascular pattern (at $4 \mathrm{~cm}$., $5 \mathrm{~cm}$., $7 \mathrm{~cm}$., and $8 \mathrm{~cm}$. from the anal verge respectively, Table IV). It would seem therefore that the observation 'absent vascular pattern' cannot be taken as a reliable indication of the presence of colitis, especially in the lower $10 \mathrm{~cm}$. of the rectum.

On the other hand, the observation 'vascular pattern present' was made on five of 67 occasions when the biopsy was grossly abnormal microscopically, and on 29 of 51 occasions when the biopsy was reported as microscopic grade 1 . Some of these latter 29 biopsies may, however, fall into the normal range in view of the microscopic findings in rectal biopsies from patients not suffering from ulcerative colitis (Table I).

It is concluded that absence of the normal ramifying vascular pattern is an unreliable sign in the description of the rectal mucosa in colitis; on the other hand, the presence of a normal vascular pattern usually excludes definite mucosal disease as seen microscopically (Table IV).

Contact bleeding The results, using this obser- 
vation, closely parallel those for vascular pattern (Table V). Two colitic patients with normal biopsies were observed to have contact bleeding; in both instances, however, the vascular pattern was present, suggesting that this bleeding was produced by excessive trauma to a normal mucosa.

Sixteen of the 70 biopsies with definite microscopic disease (grades 2 and 3 ) were obtained from areas of mucosa not exhibiting contact bleeding. This finding suggests that the presence of contact bleeding, taken independently, is not a very sensitive index of underlying microscopic mucosal disease.

Oedema The presence of oedema at sigmoidoscopy was always associated with some degree of microscopic disease in the mucosal biopsy (Table VI). However, this observation, taken independently, is shown to be an even less sensitive index of microscopic disease than contact bleeding.

Combination of contact bleeding and absent vascular pattern It is generally believed that this combination of appearances, when observed at sigmoidoscopy, is diagnostic of severe mucosal disease. This view is not entirely supported by our results which show that 13 of 51 grade 1 biopsies were obtained from areas of mucosa exhibiting this combination (Table VII). A possible explanation could be that these 13 biopsies represent the histological grade 1 abnormal mucosa, the other 38 biopsies represent normal mucosa (see Table I). Of course such a conclusion would imply that the macroscopic assessment of mucosal abnormality (absent vascular pattern and contact bleeding) is superior to the microscopic assessment in grade 1 biopsies, the group in which the pathologist is unable to distinguish between normal and early colitic changes.

The value of this combination of appearances as an index of severe microscopic mucosal disease is of the same order as that of contact bleeding alone. In fact 17 of the 67 biopsies with definite microscopic disease did not exhibit this combination of macroscopic abnormalities, illustrating that this is not a sensitive index of mucosal disease.

Overall sigmoidoscopic assessment In addition to the recording of individual criteria, an overall macroscopic assessment of mucosal normality or abnormality was made by the observer. The macroscopic appearance was recorded as abnormal if one or more of the individual criteria were found to be abnormal.

Using such a method of assessment, it can be seen from Table VIII that the mucosa was regarded as abnormal macroscopically in 65 of 70 biopsies with definite mucosal disease (grades 2 and 3 ). However, a macroscopically abnormal mucosa was also recorded in six of 35 normal biopsies, and in 26 of 52 grade 1 biopsies. One possible explanation for this discrepancy is that macroscopic abnormalities persist in the mucosa or submucosa after attacks of ulcerative colitis and that these are not detected by conventional rectal biopsy methods (Truelove and Richards, 1956; Dick and Grayson, 1961). We believe that this explanation is unlikely on the basis of an analysis of the individual criteria used to decide that the mucosa was abnormal in the various grades of biopsy (Table X). From Table X it can be seen that many of the criteria for macroscopic abnormality, especially in mucosae with a normal or grade 1 biopsy, are those which have been demonstrated to be unreliable earlier in this paper (vascular pattern absent, contact bleeding with vascular pattern present). In addition, the observations of oedema alone, or oedema in association with an absent vascular pattern, could scarcely be regarded as sufficient for a definite diagnosis of mucosal disease to be made.

It is concluded, therefore, that the macroscopic assessment of microscopic mucosal disease is often unreliable, even if only those criteria which have a high rate of observer agreement are used. It has been shown that the macroscopic assessment of mucosa with definite microscopic disease will usually be recorded as abnormal. However, many microscopically normal or near normal mucosae will also be reported as abnormal, unless the combination of contact bleeding and absent vascular pattern is used as the necessary criterion for abnormality. Unfortunately (as shown in Table VII) the adoption of such a strict criterion will prevent the macro-

TABLE X

OVERALL SIGMOIDOSCOPIC CRITERIA FOR ASSESSMENT OF RECTAL MUCOSA IN ULCERATIVE COLITIS

Biopsy Grade

Criteria of Abnormality

Reliable

Contact bleeding, absent vascular pattern, \pm oedema

Contact bleeding, vascular pattern unrecorded, \pm oedema

Unreliable

Contact bleeding, vascular pattern present

Vascular pattern absent + oedema

Vascular pattern absent only

Oedema only
Normal 1

$\mathbf{0}$

$0 \quad 0$

13
0

$2 \quad 2$

4

0
2

12

12
1

38

$\begin{array}{lll}2 & 0 & 1 \\ 2 & 2 & 1 \\ 8 & 5 & 3 \\ 1 & 0 & 0\end{array}$


TABLE XI

FREQUENCY OF CYTOLOGICAL ABNORMALITIES AND VARIOUS SIGMOIDOSCOPIC STIGMATA OF COLITIS IN PATIENTS WITH AND WITHOUT DEFINITE HISTOLOGICAL EVIDENCE OF THIS DISEASE

\begin{tabular}{l} 
Sign \\
\hline Overall sigmoidoscopic assessment abnormal \\
Loss of vascular pattern \\
Contact bleeding \\
Loss of vascular pattern + contact bleeding \\
Oedema \\
Abnormal exfoliative cytological findings
\end{tabular}

scopic diagnosis of disease in a considerable number of mucosae with definite and even severe microscopic disease.

CYTOLOGICAL ASSESSMENT OF MICROSCOPIC MUCOSAL DISEASE Using this method of assessment, it was found that on all but two of the 24 mucosae with definite microscopic disease (grades 2 and 3 ), inflammatory cells were present in the surface secretion. However, inflammatory cells were present in the surface secretion of two of 10 mucosae with microscopically normal biopsies. It is possible that such a finding could be explained by the migration of surface secretion with inflammatory cells from an adjacent or even a distant area of mucosal inflammation. It is concluded that this method is equally, and perhaps more, reliable, although certainly less convenient, than close macroscopic inspection at sigmoidoscopy for the detection of microscopically abnormal mucosa.

PRACTICAL IMPLICATIONS OF THIS STUDY Only four characteristics can be used with any confidence in the macroscopic assessment of the rectal mucosa at sigmoidoscopy in patients with ulcerative colitis, and these are (1) vascular pattern (presence or absence), (2) bleeding (presence or absence), (3) oedema (presence or absence), and (4) overall visual assessment (normal or abnormal).

The relative merits of each of these macroscopic characteristics in the detection of definite mucosal disease (biopsy grades 2 and 3) or of absent mucosal disease (biopsy grade normal) have been defined, and the results are summarized in Table XI. In compiling Table XI, the results from grade 1 biopsies have been excluded as this degree of microscopic change has been found to be present in the rectal mucosa both in colitic subjects and in normal control patients.

It will be seen that those characteristics which are reliable in the detection of microscopic disease (loss of vascular pattern, abnormal overall assessment) offset their value to some extent by occasionally indicating mucosal abnormality when the mucosa is microscopically normal. Other characteristics (oedema, the combination of bleeding and loss of vascular pattern) are of less value in the detection of microscopic disease. However, these characteristics are never present when the mucosa is microscopically normal.

The results of cytological examination of the surface secretion suggests that this method is quite as reliable as sigmoidoscopic inspection in the detection of microscopic mucosal disease, though the inconvenience of this technique lessens its practical value.

It is concluded that careful sigmoidoscopic or cytological assessment of the rectal mucosa in ulcerative colitis is a valuable indicator of underlying mucosal disease. It is unlikely that false positive diagnoses will be made if strict criteria (the combination of bleeding and loss of vascular pattern) are used at sigmoidoscopy, although a small proportion of microscopically abnormal mucosae will thereby escape detection.

Rectal biopsy is therefore an essential diagnostic step in any patient with a history suggestive of colitis, having normal or equivocal sigmoidoscopic appearances in the rectal mucosa. It is, however, of no added diagnostic value when florid sigmoidoscopic changes are present.

\section{REFERENCES}

Anthonisen, P., and Riis, P. (1961). A new diagnostic approach to mucosal inflammation in proctocolitis. Lancet, 2, 81-82.

- and - (1962). The cytology of colonic secretion in proctosigmoidal disease. Acta med. scand., 172, 375-381.

Baron, J. H., Connell, A. M., and Lennard-Jones, J. E. (1964). Variation between observers in describing mucosal appearances in proctocolitis. Brit. med. J., 1, 89-92.

Dick, A. P., and Grayson, M. J. (1961). Ulcerative colitis. A follow-up investigation with mucosal biopsy studies. Ibid., 1, 160-165.

Flick, A. L., Voegtlin, K. F., and Rubin, C. E. (1962). Clinical experience with suction biopsy of the rectal mucosa. Gastroenterology, 42, 691-705.

Matts, S. G. F. (1961). The value of rectal biopsy in the diagnosis of ulcerative colitis. Quart. J. Med., 30, 393-407.

Truelove, S. C., and Richards, W. C. D. (1956). Biopsy studies in ulcerative colitis. Brit. med. J., 1, 1315-1318. 